\title{
Developing a Web-based Learning Site for U.S. Army Aviation Students: Lessons Learned
}

\author{
Sherry L. Piezon \\ Florida State University
}

\begin{abstract}
Research determined that there were no supplemental study materials provided via electronic delivery (i.e., CD-ROM, web-based training, computer-based training, web sites) for Initial Entry Rotary Wing (IERW) students in the Primary Division of the U.S. Army Flight School, Fort Rucker, Alabama. Informal surveys were conducted to gather information regarding implementation of electronic delivery. Survey results indicated a positive attitude and desire for electronic instructional media. Therefore, the main focus of this project was development of a web-based learning site that would directly support current instructional objectives of the Primary Division. This paper examines lessons learned during the
\end{abstract} developmental and implementation process.

\section{INTRODUCTION}

The primary purpose of the Initial Entry Rotary Wing program at Fort Rucker is to prepare new aviation students for assignments as rated aviators in tactical aviation units worldwide. In addition to their flight training, students receive ground training in aviation related studies which include but are not limited to navigation, aerodynamics, aeromedical, meteorology, and emergency procedures. Flight school is divided into several sections. Each of these sections has a specific focus and requires successful completion of a checkride and oral examination.

The Primary Division in the IERW program includes the first ten weeks of flight training. During these ten weeks, students are provided both flightline and classroom training. The classroom training is designed to supplement flightline training. However, due to classroom time constraints, students are often exposed to topics at the flightline that have yet to be covered in the classroom. In addition, it is not uncommon for classroom activities to be briefer than the expectations of the flightline instructors.

Although students receive written handouts, these handouts are designed as study guides for classroom examinations, which may lack the depth required to pass oral examinations at the flightline. Neither classroom nor flightline instruction includes the integration of instructional media with the exception of video. Video footage is limited and used sparingly. Instructional media such as Flash, Shockwave, or even simple animations are relatively non-existent.

Lack of planning for future improvements appears to be due to a lack of funding rather than a lack of interest. Funding has been provided for multimedia enhancement of leadership courses and replacement of existing correspondence courses. There is an ongoing interest in development of web-based and multimedia courses. The Army has recognized that these technologies have the potential to save money by reducing travel costs, allowances, and printing correspondence material (TRADOC, 2003b). However, at this time, only specified courses have been identified for enhancement or conversion. Since the IERW student is already on location for other training, little cost savings can be identified for converting or enhancing classroom courses.

During informal interviews, students professed an interest in digital multimedia tutorials, study guides, and learning games. Although there may not be a cost saving potential or a need to convert existing classroom courses, there are other reasons for developing web-based multimedia programs. Characteristics of today's student are continually changing and with every new class comes a more technology savvy group of individuals. Students today may benefit from development of web-based multimedia. Whereas students previously used libraries and reference manuals to conduct research, today's students are increasingly turning to web-based references and search engines for their research pursuits. Therefore, if students are seeking information online, it only seems prudent to begin to develop 
reliable and trustworthy web sites that students can access rather than to leave their research to chance.

\section{REVIEW OF LITERATURE}

The utilization of computers and the internet to enhance, support, or host training and education is not a new idea. In fact, Dr. Seymour Papert was pioneering an effort to revolutionize education with personal computers as early as the 1960's (MaMaMedia, 2000). Developing computer-based instruction (CBI) modules for learning can be placed on stand-alone computers or put on CD-ROM and mailed to individuals for use on any computer. So why should educators bother with the Web? Greenberg and Lakeland (1999) suggest that ease of development and access are two primary reasons for utilizing the web for instructional facilitation. In addition, the reach in terms of geography and time become boundless. Individuals seeking information on any number of topics are only as far away as the nearest computer with an internet connection.

Although the ability of the personal computer and the internet to deliver education and training is not at dispute, the quality and extent of its capabilities have long been disputed. The dispute seems equally divided between those who believe the Internet will revolutionize the educational industry and those who believe the capabilities of computers in the classroom have been oversold and underused (Cuban, 2001). In fact, many internet enthusiasts have come to believe that the internet will become a primary distribution system for education and training at a distance (Simonson, Smaldino, Albright, \& Zvacek, 2000).

The use of computers and the internet to impact education is not limited to K-12 or Higher Education. Many working adults find it increasingly difficult to schedule supplemental education between their work and personal lives. In addition, many corporations are discovering cost savings by allowing a percentage of their employees to telecommute. Online courses allow students the opportunity to save the cost of travel and still fulfill their work obligations while completing studies at their own pace (Simonson et al., 2000). In addition to cost savings, students gain exposure to collaborative learning opportunities that may not be available on a traditional campus. Individuals, educators, and researchers have discovered new opportunities to collaborate, communicate, create accessible databases, and conduct research all from the comfort of their own homes.

While the apparent cost-benefit analysis may be appealing for many employers, it is wise to be cautious regarding the application and scope of technology. Improperly designed or implemented technological media can result in an expensive and inefficient endeavor (Shank \& Sitze, 2004). Therefore, it is a good idea to approach distancelearning initiatives carefully. A careful examination of the reliability and stability of supporting platforms may save substantial frustrations and monetary investment in the long run.

\section{METHOD}

The instructional model used for the development of the Aviation Trainer web-based learning site was the Interservice Procedures for Instructional Systems Development (IPISD) (Branson, 1975). The Center for Educational Technology at Florida State University and the U.S. Army Combat Arms Training Board at Fort Benning, Georgia contracted the preparation and development of this model. This model serves as a developmental standard for the Army, Navy, Marines, and Air Force. The model consists of five phases. A single individual or a team can complete these five phases.

The main goal of this project was to develop a professional, user friendly and accessible web site for the students and instructors of the IERW Primary Division. However, one may ask why a model that is nearly 29 years old and developed before the wide use and dissemination of desktop computers would be used as a development model for a web-based learning site. The answer lies in the original purpose of the IPISD model. As stated previously, this model was developed as an "interservice" model. The main purpose of developing an interservice model is to streamline interchangeability, coordination, and training across military services. However, this did not limit each of the individual services from amending the model as appropriate for that individual service. After review and adoption, the U.S. Army Training and Doctrine Command (TRADOC) converted the model to an Army publication (TRADOC Publication 350-70). 
Since the original conception of the IPISD model, the U.S. Army has updated TRADOC Publication (TP) 350-70 to reflect current technology and new research/theory. In addition, several supporting documents have been developed to provide detailed information in areas of interest.

Many of these publications are still in draft format and were not used due to their status. However, TP 350-70-2 was of significant applicability to this project. This publication provides guidance for producing interactive multimedia instruction. This document outlines a process to plan, design, develop, and validate multimedia courseware (TRADOC, 2003b). This pamphlet was used extensively in actual development of multimedia products incorporated into the Aviation Trainer web site. However, this paper will not concentrate on a detailed technical description of how each multimedia lesson was developed. Rather, this paper will focus on lessons learned while utilizing this methodology to develop a web-based learning site.

\section{RESULTS}

A multimedia web site was developed to support the Primary Division students of the IERW program at Fort Rucker, Alabama. Five instructors reviewed content and layout during the design and development stage. Several errors in content were identified and corrected during this evaluation phase. After development, a formative evaluation was conducted with IERW students, instructors, and managers. Informal interviews were conducted face-to-face and via e-mail. Participants provided feedback regarding site usability, layout, appearance, and future recommendations for content.

Instructors interviewed indicated that the web site provided easily accessible tutorials and study guide. Instructors particularly liked the ability to provide instant reference material for new students. Managers expressed a desire to share the web site with new students but also raised concerns regarding proprietary issues of some materials provided. Positive student comments included easy accessibility, no cost, current/updated information, and use of "plain language." Students expressed an interest in and enjoyment of educational games. Negative comments primarily surrounded the learning environment and included low bandwidth access (slow download of study guide), lack of access to a personal computer, waiting times for computers at the learning center, and family distractions. Other negative comments concerned font size, download information, and size/orientation of graphics. All negative comments were addressed during the formative evaluation. Changes involved removing questionable proprietary content, updating font size/type, converting graphic size/orientation, and providing download information for users. Bandwidth issues were addressed by reducing file sizes and providing alternate download options. Environmental factors outside the scope of this project were not addressed (i.e., learning center, family distractions). Overall, reaction to the web site was positive and enthusiastic. Students and instructors felt the site was useful as a study guide and reference for Primary Division flight training.

A site statistics program (LiveStats) was used to collect information regarding site traffic, content accessed, geographical locations accessing site, access times, number of hits, number of visits, and other useful tracking information. A "hit" is recorded each time a user accesses a page or graphic on your site. A "visit" is recorded each time your web site is accessed by a user. LiveStats provides "unique visitor" tracking which provides more reliable and detailed information about your site visits (DeepMetrix, 2003). These statistics are helpful in determining user characteristics and are provided at no charge by the hosting service. Knowledge of these user characteristics assisted the designer in making informed decisions regarding web site content and management. The traffic for the web site was much higher than anticipated for the first month online. Initial estimates for site visits and hits were low (200 to 300 ) based on the site's lack of advertising and total student population of approximately 300 at any given time. The interest generated by visitors other than students, instructors, and managers was unanticipated and accounted for a large amount of site traffic. The site was launched in March of 2004. During the month of March, LiveStats recorded a total of 1,250 visits which accounted for a total of 55,941 hits.

Based on initial site statistics and feedback received during and after the formative evaluation, the Aviation Trainer Web Site is providing digital multimedia content that both 
students and instructors find beneficial. Although it would be difficult to directly attribute use of the web site to student success on checkrides, several students who used the web site and successfully passed the end of phase checkride commented that the site was extremely useful as a checkride study guide. Sample data were not collected for postcheckride students regarding web site use and benefits due to lack of student access. Students who participated in the web site rollout voluntarily provided positive feedback after checkride. Future research is planned to capture post-checkride data via survey, interviews, or student scores on checkride.

\section{DISCUSSION}

The following topics outline the lessons learned during the design, development, and implementation of the Aviation Trainer web site. As mentioned previously, the main goal of this project was the development of a web-based learning site that would directly support current instructional objectives of the Primary Division. The lessons learned are categorized into three categories. Many of the lessons learned fell into more than one category. This is especially true in the case of building a professional and accessible web site. Since these two categories go hand-inhand, the lessons learned for these two categories were summarized together.

\section{Professional and Accessibility Lessons Learned}

\section{Using Templates}

The web site was originally designed to be of assistance for a small number of students attending IERW. Minimal growth was anticipated, as was the volume of intended content. Therefore, the original web pages were developed without aid of templates. Since the number of web pages planned was minimal, it was felt that updating these pages would be a small task. The unanticipated usage and popularity of the site dictated that additional content and pages be added. The addition of content and web pages soon became demanding when updating navigational links on an individual web page. The use of templates would have avoided this problem altogether. Although current content pages were updated to templates, organization and structure did not support template usage and the structure quickly became unmanageable. This became most apparent during the formative evaluation when errors were discovered in content.

Underestimating site popularity and usage level can lead to increased workload, site down time, increased hosting fees, and frustrated users. A site redesign resolved this issue for the Aviation Trainer web site. Down time for this site was minimal since the redesign was completed off-line and then uploaded upon completion. However, these resources may not always be available to a site designer and would have been unnecessary if proper planning had been in place from the beginning. The redesign included templates with editable and non-editable regions. Site navigation and external links are embedded in non-editable regions. This now prevents inadvertent changes to site navigation and makes updating navigation on the entire site quick and painless. It is vital that a site be designed to accommodate unexpected changes in traffic and navigational links. Regardless of initial size of the site, leaving room for expansion is imperative.

\section{Keeping a Journal}

Flanders and Willis (1998) strongly recommend use of a development journal. These parameters include font sizes, types, color palette choices, navigation schematics, picture sizes, compression, resolution, tags, and other pertinent information one might forget over time.

\section{Using Well Defined Folders}

This site was originally expected to contain a small number of files. Therefore, definitive folders for items such as borders, pictures, resources, and individual tutorials were not created. This resulted in chaos when site content expanded. It became nearly impossible to track down a single file without well defined folder delineation. When the site was redesigned, great effort was made to create folders for each element that were both logical and easy to navigate.

\section{Checking Site Statistics}

As stated above, it is important for a webmaster to understand how site statistics can assist in site management and future planning decisions. Not all hosting services offer site statistics. Of those hosting services that offer this service, it may be limited at best. It is important to choose a hosting service that provides 
information you need. The Aviation Trainer web site utilizes FinestHost. This hosting service provides competitive hosting fees, discounts for resellers, and LiveStats site statistics. When choosing a hosting service that provides site statistics, designers should compare statistical packages. Statistical information that might be considered important is total number of hits per day/month, total number of visits, popular pages/documents, countries and states accessing the site, trends, and the Internet Service Provider (ISP) of frequent visitors. Examining site statistics can provide an overall picture of how the site is being used and who the audience includes. It is important to consult the statistics of a site to determine what, if any, changes need to be made to the site navigation and content.

The term "hits" is commonly used and remains highly acceptable to the general web development community. A "hit" is a measure of the number of times a page is accessed by a user. Unfortunately, hits are an inaccurate measure of web site statistics. The problem with measuring site hits is that every graphic on the page is included in the count (DeepMetrix, 2003). Since this site statistic can result in misleading information, web developers began searching for a better way to interpret site traffic that would be more meaningful for their industry. The next evolution in site statistics is "page views." Page views are number of times a web page is viewed. This solved the problem of recording multiple hits for one web page but page views still have their pitfalls. When proxies and caches become involved, page views can also become a misleading measure. One answer to this dilemma is measuring visits and sessions. This statistic can measure page views per visit, which may be an indication of customer interests. While it is significant to note page hits, views, and visits, it is more important to understand what documents or information visitors are viewing. This will provide insight into what new types of data should be incorporated into future additions or changes to web site content. It is important to look at site statistics as a whole rather than focusing on individual numbers in isolation.

For example, based on predictions, it was extremely surprising to discover that the total number of hits for March 2004 exceeded 55,000. To determine whether this number was deceptive, the number of visits for the month was compared.
For the month of March, 1231 site visits were recorded. As stated above, it is important for a web developer to understand how to read their site statistics. For example, in the month of March a total number of 55,941 hits were reported. The next line in the report lists average number of hits during "a month" as 8,498 . At a quick glance, the reader may assume that 55,941 divided by 31 (days in March) should equal 8,498.18. In fact, the key words are "a month." This phrase indicates the average number of hits across the months the site has been active. These data are important when examining a trend analysis on your site. This example reinforces the point that the reader of a site statistics report should be familiar with how the data is reported in order to reap the benefits of the information provided. It cannot be emphasized enough that site statistic reports are only as good as the reader is thorough.

\section{Selected Media}

Selection of media for web-based learning web sites is of critical importance. Although there are many instructional development programs available commercially, none of these programs offer a complete solution for all web site development features. Interestingly, eighteen separate programs were used to develop the site content for the Aviation Trainer web site. The programs selected for this project were based largely on programs available to the site designer at a low or no cost. Although it would have certainly been possible to limit the number of programs utilized, it is still important to recognize monetary investment required to undertake such a project. When selecting programs for web development, it is suggested that program managers determine design team expertise and develop a comparison checklist that lists program strengths, limitations, and cost. This will ensure that the team is provided with the best software for the most reasonable price. In addition, educators considering undertaking a web development project should also recognize their limitations regarding web development expertise. Although it is not impossible to develop a webbased learning site as an individual, the Aviation Trainer web site is an example of the limitations that an individual may encounter. Of particular consideration is the level of programming expertise available to the developer. Without at least a basic programming background, it will be 
difficult to develop sophisticated training modules. However, for those with limitations in this area, there are off-the-shelf programs that are available that will aid in circumventing the programming process. However, it is important to note that a large majority of the programs will also limit the applicability and flexibility of the learning modules.

\section{User Friendly Lessons}

\section{Checking Browsers}

When developing web pages, it is important to understand that web pages will be viewed differently depending upon the browser they are being displayed within. However, something that may catch a designer by surprise is inaccurate reporting regarding browser capabilities. This was encountered after using CourseBuilder to develop several tutorials. CourseBuilder is a free add-on tool for Dreamweaver. According to the CourseBuilder user guide, this software was supported by both Netscape and Internet Explorer in versions later than 3.0. This turned out to not be the case. Although Netscape will display the content, it does not support some of the interactions in the tutorials. Some of these interactions were critical to success of the tutorial since they were included in the evaluation and quiz portions of the tutorial. This may vary significantly based on browser and version. It could be difficult to find abnormalities like this one until the tutorial is loaded. After reviewing the site statistics to determine user browsers and versions, there was little if any effect on The Aviation Trainer web site. There were no user reports of inaccessibility due to browser incompatibility. However, this may not always be the case. It is a good idea to test these features prior to completing an entire tutorial. This will prevent wasted design and implementation time.

\section{Connection Speeds}

It is important to always consider connection speed of the users. In the case of this project, students living on post only had access to $56 \mathrm{~K}$ modem connection. Students accessing the web site from the learning center were subject to the post server access speeds, which can vary greatly throughout the day. This significantly limits the ability to use large graphics, movies and audio files. Consideration should be given to the overall size for each web page. Large page file sizes result in long downloads on slow internet connections. Forcing the user to wait for longer than six to eight seconds for a page to download can lead to frustration. This frustration may cause the user to stop the page download and abort any intentions of viewing the site. On this site, every attempt was made to ensure that the page sizes were as small as possible without compromising page content. Where file size could not be reduced, alternate accessibility was provided (i.e., study guide).

\section{CONCLUSION}

There are many other considerations when building a web-based learning site than those listed above. However, this paper focused on some of the more costly and confusing aspects of web development as well as those that presented a significant obstacle during the development of the Aviation Trainer web site. Prior to undertaking a project of this size, managers should consider potential costs and unexpected costs of site development (i.e., hosting fees, revisions). Costs may vary widely based on personnel available, their expertise, and outsourcing costs. It is also important to recognize that the learning site may evolve over time based on student, instructor, and industry demands. The most significant consideration an educator can give to a web-based learning site is the ability to be flexible and adaptable over time. 


\section{REFERENCES}

Branson, R.K. (1975). Interservice procedures for instructional systems development: Executive summary and model. Tallahassee: Center for Educational Technology, Florida State University.

Cuban, L. (2001). Oversold and underused: Computers in the classroom. Cambridge: Harvard University Press.

DeepMetrix. (2003). Unique visitor tracking - The truth, from http://www.deepmetrix.com/livestats/net/ whitepapers/index.aspx.

Flanders, V., \& Willis, M. (1998). Web pages that suck learn good design by looking at bad design. Alameda: Sybex Inc.

Greenberg, J., \& Lakeland, J.R. (1999). Building professional web sites with the right tools. Upper Saddle River: Prentice Hall.

MaMaMedia. (2000). Seymour Papert, from http://www.papert.org.

Shank, P., \& Sitze, A. (2004). Making sense of online learning. San Francisco: Pfeiffer.

Simonson, M., Smaldino, S., Albright, M., \& Zvacek, S. (2000). Teaching and learning at a distance: Foundations of distance education. Upper Saddle River: Prentice-Hal, Inc.

TRADOC. (2003a). TP 350-70-1: Collective training. Fort Monroe: U.S. Army Training and Doctrine Command.

TRADOC. (2003b). TP 350-70-2: Multimedia courseware development guide. Fort Monroe: U.S. Army Training and Doctrine Command. 